\title{
Religião e Cura: Algumas Reflexões Sobre a Experiência Religiosa das Classes Populares Urbanas ${ }^{1}$
}

\section{Religion and Cure: Some Thoughts on the Religious Experience of Urban Popular Classes}

\author{
Miriam Cristina Rabelo ${ }^{2}$ \\ RABELO, M. C. Religion and Cure: Some Thoughts on the Religious Experience of Urban \\ Popular Classes. Cad. Saúde Públ., Rio de Janeiro, 9 (3): 316-325, jul/sep, 1993. \\ The importance of religious cults in providing healing services for Brazil's urban poor is now \\ widely acknowledged. This study focuses on a poor neighbourhood in Salvador and the history \\ of the illness of a young woman who resorted to several religious therapies beginning at the \\ time of onset of her disease. The article seeks to contribute to an understanding of the ways in \\ which the world views and healing projects of various religions are actually incorporated into \\ the experience of ill individuals and their family members.
}

Key words: Religion; Cure; Therapies; Culture and Illness; Urban Brazil

\section{INTRODUÇÃO}

O estudo da religiosidade das classes populares urbanas tem apontado para o papel central dos cultos religiosos, enquanto agências terapêuticas (Monteiro, 1977; Montero, 1985; Greenfield, 1992). Em bairros populares de Salvador, a pluralidade de cultos que oferecem serviços de cura salta aos olhos, levantando a importante questão de se compreender como os indivíduos se utilizam de tais serviços para lidar com a experiência da aflição. Este trabalho visa levantar algumas questões acerca da experiência religiosa de habitantes de um bairro pobre de Salvador, o Nordeste de Amaralina, enquanto experiência que é, em grande medida, construída em termos de busca de solução para problemas de doença e aflição.

Vários estudos têm-se voltado para uma análise das diferentes estratégias pelas quais as religiões reinterpretam a experiência da doença e modificam a maneira pela qual doente e

\footnotetext{
${ }^{1}$ Trabalho apresentado no XVI Encontro Anual da ANPOCS, GT - Religião e Sociedade.

${ }^{2}$ Centro de Estudos Etnoepidemiológicos e SócioAntropológicos da Saúde (Cesame), Departamento de Sociologia da Universidade Federal da Bahia. Rua Padre Feijó 29, $4^{\circ}$ andar, Salvador, BA, 40110-170, Brasil.
}

comunidade percebem o problema (Turner, 1967; Levi-Strauss, 1967, 1975; Kapferer, 1979; Comaroff, 1980; Kleinman, 1980; Csordas, 1983). Perpassando tais estudos está o argumento central de que as terapias religiosas curam ao impor ordem sobre a experiência caótica do sofredor e daqueles diretamente responsáveis por ele. Na maioria dos casos, as terapias religiosas são abordadas sob a perspectiva do culto enquanto campo organizado de práticas e representações, ao interior do qual o especialista religioso manipula um conjunto dado de símbolos para produzir a cura. Para que os símbolos religiosos funcionem, isto é produzam cura, é preciso que sejam compartilhados pelo curador, o doente e sua comunidade de referência; usualmente, toma-se como pressuposto este compartilhar de símbolos e significados entre os participantes do processo de cura. Aqui pretende-se examinar os tratamentos religiosos sob a perspectiva do paciente e daqueles diretamente responsáveis por ele. Muitas das histórias que contam sobre casos de doença revelam um percurso complexo entre diferentes serviços terapêuticos, tentativas - nem sempre bem sucedidas - de lidar com visões conflitantes do problema e incertezas, quanto à causa da doença e o resultado dos vários tratamentos procurados. 
O fato de que no Nordeste de Amaralina as pessoas, freqüentemente, transitam por diferentes cultos de cura mostra claramente que doença e cura são realidades construídas intersubjetivamente, não apenas no sentido de que o terapeuta religioso deve agir sobre as percepções do doente e de seus familiares, mas também porque estes estão continuamente negociando significados tanto ao interior dos cultos como fora deles. Neste sentido, a cura não é o resultado direto de medidas terapêuticas, realizadas ao interior do culto mas uma realidade por vezes bastante frágil que precisa ser continuamente negociada e confirmada no cotidiano do doente e dos membros de suas redes de cuidado e apoio. Esta idéia da cura enquanto realidade processual é vividamente expressa nas histórias sobre casos de doenças, produzidas pelos habitantes do Nordeste de Amaralina. Estas histórias fornecem uma chave importante para a compreensão das formas pelas quais as visões de mundo e projetos de cura de vários cultos religiosos são, de fato, incorporados à experiência cotidiana de doentes e seus familiares.

\section{A CONSTRUÇÃO DA DOENÇA}

Aqui proponho examinar o caso de doença de uma jovem moradora do Nordeste de Amaralina. Adelice, conhecida no bairro como MexeMexe, sofre de problemas mentais desde a adolescência. Sua mãe, Benedita, tem recorrido a uma série de serviços terapêuticos, incluindo diferentes cultos religiosos, em busca de uma solução para a doença. Embora tratando-se de um caso de doença mental, a história de Adelice é bem ilustrativa de uma trajetória que liga membros das classes populares a cultos religiosos. Utilizo essa história para compreender como interagem, em contextos concretos, símbolos religiosos e práticas sociais.

A Adelice tem 28 anos e mora com sua mãe, padrasto e irmãos em uma ruela estreita do Nordeste. Diferentemente das outras ruas do bairro, nesta a maioria das casas tem grades segundo me foi explicado trata-se de medida de proteção contra os ataques constantes da louca Mexe-Mexe, uma das mais temidas malucas do
Nordeste. Mexe-Mexe vagueia pelas ruas do bairro, entrando nas casas sem ser convidada e jogando pedra em qualquer um que cruze o seu caminho. Sua chegada é logo anunciada pelos gritos desafiadores das crianças. Em sua própria casa, Adelice não parece ser a maluca MexeMexe de que tanto se fala. É quieta e reservada. Segundo Benedita é a provocação das crianças do bairro que a torna violenta.

Segundo me conta Benedita, a doença de Adelice começou quando tinha quinze anos. A partir de então passa a ser vítima de ataques freqüentes: cai no chão se debatendo, o corpo enrijece, a língua embola. Seus gritos parecem os urros de um animal. Com o tempo o problema se agrava. Enquanto na adolescência se exige das moças que mantenham certa distância com relação ao mundo da rua, Adelice habituase a fazer incursões constantes e diárias pelo bairro, sem nenhum motivo aparente. Força sua entrada nas casas sem ser convidada. Mais sério ainda, desenvolve comportamento violento durante seus passeios. Freqüentemente ela mesma é agredida: certa vez, me conta Benedita chocada, deram-lhe uma chicotada no rosto como se ela fosse um animal.

Embora os seus ataques só tiveram início quando fez quinze anos, Adelice sempre fora diferente. Quando criança era excessivamente quieta, não brincava com outras crianças e estava sempre se escondendo pelos cantos. Mais tarde mostra-se "rude nos estudos", não conseguindo acompanhar a lição da escola. Moça grande e desajeitada, chateiam-na por ter jeito de homem. Reinterpretando o passado sob a luz do estado atual de sua filha, Benedita agora vê nestes eventos sinais dos problemas que ainda estavam por vir. De fato, embora a eclosão da doença de Adelice possa ser situada em um momento específico de sua biografia, uma série de eventos parece ligar passado e presente, antes e após o início da doença em termos de uma imagem de alteridade: Adelice sempre foi rude, as pessoas ridicularizam-na por seus modos masculinos, ela urra como um animal durante os ataques e é espancada no rosto como se fora um animal. Expresso nestes eventos esta sua identidade ambígua e problemática: uma criança que não aprende (e cuja rudeza nos estudos talvez a aproxime dos animais), uma 
mulher a quem falta feminilidade (e cuja ligação estreita com o mundo da rua a aproxima do universo masculino), uma pessoa tratada como se fora um animal (e cujo desrespeito a normas de sociabilidade talvez a aproxime dos animais).

A trajetória de Benedita por vários serviços de cura é, também, uma busca de meios para lidar com essa identidade ambígua de Adelice. Apegando-se ao diagnóstico médico de foco que foi atribuído a Adelice em um dos hospitais onde se tratou - Benedita procura contrapor-se às visões da comunidade para quem Adelice é louca. Incorporado ao discurso popular sobre doença mental, foco é tido como uma doença da cabeça, assim como, por exemplo, pneumonia é doença dos pulmões. Para Benedita isso significa que o problema de Adelice é semelhante a qualquer outra doença física: afeta uma parte do seu corpo (como comprovam os exames médicos) e pode ser tratado com o uso constante de remédios (os ataques de Adelice são, de fato, controlados com o uso de medicação). Sob essa perspectiva, se Adelice deve ocupar o papel de doente, ela não merece o estigma de louca.

Enquanto Benedita reduz o problema de Adelice aos ataques (que os médicos diagnosticam como foco), a comunidade ressalta suas constantes e violentas romarias pelo bairro. São estas que lhe valem o estigma de maluca. Contra as visões da comunidade, Benedita procura mostrar uma lógica por trás do comportamento violento de Adelice: trata-se de uma reação à perseguição das crianças locais. Entretanto, precisa ainda justificar as constantes saídas de Adelice, que por si só constituem um problema.

A ânsia que tem Adelice de ir para a rua não é vista por sua mãe como, simplesmente, mais um sintoma de sua doença; por vezes Benedita dá a entender que se trata de problemas distintos. No centro espírita oferecem-lhe uma explicação para a doença de Adelice que combina disfunção orgânica e intervenção espiritual: onde o corpo está fraco, os espíritos tendem a pairar. Se os ataques de Adelice são um resultado direto do foco, a sua vida na rua advém da ação de espíritos que se "aproveitam" de um problema médico inicial.

\section{A EXPERIÊNCIA AO INTERIOR DAS TERAPIAS RELIGIOSAS}

A explicação oferecida pelo espiritismo ao problema de Adelice repousa em uma distinção bastante comum entre doenças materiais (orgânicas) a serem tratadas por médicos e doenças espirituais pertencentes à esfera de competência dos especialistas religiosos. No caso de Adelice esta distinção parece bem definida: Adelice tem uma desordem física (foco) que provoca os ataques e uma desordem espiritual que a compele à rua. Na prática, entretanto, os limites que separam estas duas ordens de aflição tendem a se dissolver e especialistas religiosos são, freqüentemente, chamados a lidar com os mesmos sintomas que os médicos. Assim, embora pacientes e terapeutas populares, constantemente, se refiram às fronteiras entre doença de médico e doença espiritual não há uma nosologia popular ou religiosa que classifique doenças de acordo com a base física ou espiritual dos sintomas: a questão é sempre sujeita a contínua revisão.

Para resolver o problema de Adelice, Benedita recorreu a serviços psiquiátricos, a oito casas de candomblé, a uma igreja pentecostal e a um centro espírita. As terapias religiosas não implicaram abandono de tratamento com os médicos: segundo Benedita todos os especialistas religiosos que consultou concordaram, quanto à necessidade de tratamento paralelo com médicos. De fato, pacientes e líderes religiosos populares negociam continuamente com o poder da medicina moderna de modo a garantir para si um espaço próprio de práticas e representações. Invocando a ação de diferentes entidades na causação da doença, terapeutas religiosos colocam-se em uma posição bastante conveniente: não apenas afirmam dividir responsabilidade com a medicina moderna, mas julgam intervir onde esta revela-se incapaz. Enfatizando a importância do diagnóstico e tratamento médico ao longo do caso de Adelice, Benedita consegue garantir a sua filha acesso a um papel de doente socialmente legitimado.

A primeira religião que Benedita buscou para resolver o problema de sua filha foi o candomblé; durante anos ela transitou por vários terreiros dentro e fora do bairro. A relutância 
com a qual Benedita hoje fala do candomblé parece, de certa forma, refletir o status marginal do culto na sociedade mais ampla: os poderes invocados no candomblé são essencialmente ambíguos e, portanto, potencialmente maléficos. Benedita agora avalia suas idas ao candomblé como perda de tempo e dinheiro, motivadas pelo seu desespero frente à agonia de Adelice. No desespero, justifica, segue-se qualquer conselho.

Apesar do seu descaso atual pelo candomblé, ao explicar a fonte da aflição de Adelice, Benedita ainda mantém a versão construída em um dos terreiros a que recorreu. Lá, a mãe de santo ofereceu-lhe uma explicação "espírita" para o sofrimento de Adelice: tratava-se de aflição causada pelo espírito de um parente morto, que por gostar demais de Adelice, prende-se ao seu corpo após a morte. Benedita não demorou a descobrir a identidade do espírito malfeitor: é seu irmão mais novo que durante algum tempo morou em sua casa e que ela julga ter estado apaixonado por Adelice. $\mathrm{O}$ jovem tio de Adelice tinha uma predileção especial pela rua, paixão que Adelice agora manifesta, e sua morte antecede imediatamente à eclosão da doença da sobrinha.

A interpretação é dimensão central do candomblé onde pais e mães-de-santo são tidos como possuidores de poder para descobrir as causas ocultas da aflição dos seus clientes (Williams, 1979; Alves, 1990; Rabelo, 1990). Ao consultar um pai-de-santo, o indivíduo espera prover o mínimo de informação possível sobre seu caso; é o especialista religioso que deve falar, provando seu conhecimento do quadro de relações (visíveis e invisíveis) que compõem o contexto da doença.

No candomblé, interpretar a aflição é elaborar uma narrativa que reconstitua a cadeia de eventos que levaram o indivíduo a doença e que aponte para a direção do tratamento e da cura. Se, neste sentido, podemos dizer que cabe à mãe-de-santo organizar a experiência caótica do sofredor e daqueles diretamente envolvidos no caso, é preciso também considerar que o sucesso da atividade divinatória depende largamente da capacidade destes últimos de se reconhecer na narrativa do especialista e, assim, encaixar sua própria versão dos eventos naquela construída pelo adivinho (Rabelo, 1990). O fato de que
Benedita tenha sido capaz de identificar seu irmão como o parente morto referido na estória da mãe de santo significou que se produziu um afinamento de vozes e discursos: Benedita resignificou a aflição de sua filha de acordo com o modelo oferecido pela mãe-de-santo, um modelo que, em certa medida, foi capaz de prover uma confirmação poderosa e autoritária a algumas de suas próprias suspeitas.

Segundo este modelo, a lógica subjacente ao comportamento estranho de Adelice reside não nela mesma mas no outro invisível que se apega a ela e que impõe seus hábitos masculinos sobre o seu corpo. A incapacidade de Adelice de permanecer em casa (como devem as mulheres direitas quando fora do trabalho) é expressão do gosto que tinha seu tio pela vida na rua. A partir dessa perspectiva, a identidade ambígua e problemática de Adelice é vista como resultado da superposição de duas identidades distintas: a do seu tio e a dela própria. $\mathrm{O}$ tratamento visa colocar Adelice em uma posição protegida e vantajosa para melhor relacionar-se com as forças e poderes imprevistos do meio. Envolve uma série de medidas para limpar o corpo de Adelice (banhos, fumigação), bem como negociação necessária com Exu (que para Benedita não é nada mais que o diabo), através de despachos.

Benedita não viu resultado no tratamento de Adelice nas oito casas de candomblé a que recorreu, embora permanecesse apegada à explicação que lhe foi dada por uma mãe-desanto. Segundo me conta, os sintomas de Adelice persistiam sem que os terapeutas do candomblé fossem capazes de reverter ou ao menos de justificar o quadro. É nesse contexto que recebe a visita de missionários pentecostais interessados em expandir sua influência no Nordeste e acaba por tornar-se freqüentadora do culto.

Na Igreja Universal do Reino de Deus, a doença de Adelice é re-significada de acordo com um modelo que opõe radicalmente bem e mal. A doença é provocada por forças de Satanás que devem ser expulsas do corpo. A cura marca o início de um processo pelo qual, liberto do mal, o sofredor entra no mundo dos fiéis.

No culto pentecostal ao qual se filia Benedita, a cura é encenada como uma batalha na qual o 
pastor, suas obreiras e o círculo de fiéis em oração juntam suas forças contra as entidades do mal alojadas no corpo do doente. Colocando suas mãos sobre a parte doente do corpo o pastor comanda Satanás e comparsas a sair. Sua voz ríspida e desafiadora gradativamente se mistura às vozes das obreiras e demais participantes, cada qual enunciando sua própria oração. A atmosfera é tensa, da confusão de vozes e orações pode-se ouvir as palavras "Sai, sai, sai" que marcam o fim de cada oração, o momento em que o pastor retira bruscamente suas mãos do doente. O processo é repetido algumas vezes até que se produza consenso quanto aos resultados benéficos da oração. Mudanças no comportamento do paciente choro, tremor, ataques - são altamente valorizadas como sinais de que as entidades do mal foram atingidas e finalmente forçadas a se manifestar.

Estranhamente, ao falar do tratamento de Adelice na igreja pentecostal, Benedita enfatiza as similaridades entre esta última e o candomblé. Segundo ela, em ambos os cultos o diabo é o foco principal das atenções. Benedita também queixa-se do barulho - o pastor grita no microfone - e da rudeza com a qual o pastor trata os espíritos. O fato de que Adelice não tenha sofrido melhora após as sessões de cura na igreja, nem tampouco tenha exibido sinais da manifestação dos espíritos supostamente alojados em seu corpo, sugere que a visão pentecostal de doença como resultante da invasão de entidades do mal pode levar à imputação de uma identidade negativa sobre o próprio doente. Caso a aflição persista e o demônio causador da doença não se revele, então a entidade maléfica e seu hospedeiro tendem a tornar-se um. Repetidamente dirigindo insultos e desafios aos espíritos no corpo de Adelice, o pastor gradativamente impõe uma imagem negativa sobre a própria Adelice. Não é raro que tendo falhado em produzir uma mudança na maneira pela qual o doente percebe seu estado (isto é não obtendo sucesso na expulsão do mal) os terapeutas pentecostais reorientem seu discurso e passem a enfatizar a condição de pecado do doente como obstáculo à cura.

Benedita critica candomblé e pentecostalismo, segundo a perspectiva do culto espírita ao qual se filiou. A ideologia de caridade que é central ao espiritismo permeia, tanto sua proposta específica de prática social (voltada para programas assistenciais, de educação e distribuição de alimentos aos pobres, por exemplo), como sua proposta de cura via educação ou persuasão das entidades causadoras do mal (Warren, 1984; Greenfield, 1992). No centro espírita que freqüentou Benedita, os espíritos que provocam a doença são tratados com gentileza como se fossem crianças que precisam ser ensinadas a se comportar de maneira apropriada e motivadas a substituir a ação destrutiva, causadora da doença, por uma ação construtiva e benéfica. Os "obsessores" que causam a doença são espíritos menos desenvolvidos, para cujo progresso moral os médiuns podem contribuir. A metáfora da batalha que orienta a cura no culto pentecostal e que justifica a atitude agressiva do pastor frente aos espíritos é substituída pela imagem do ensinamento dedicado: a cura é essencialmente uma tarefa pedagógica pela qual espíritos menos desenvolvidos são conduzidos a estágios superiores de existência.

O ensinamento no espiritismo se dá em dois níveis principais. No primeiro, doentes e familiares se reúnem para ouvir as pregações do presidente do centro: livretos contendo os principais ensinamentos do culto são também distribuídos. No segundo nível, a ação é dirigida aos espíritos mesmos responsáveis pela doença. Em tais ocasiões, o doente e seus acompanhantes são conduzidos a um encontro mais privado com médiuns do centro. A sessão se inicia quando um dos médiuns é manifestado do espírito que se aloja no corpo do doente; então passa a desenrolar-se um diálogo entre especialistas religiosos e espírito cujo conteúdo é claramente pedagógico: o espírito deve ser persuadido a mudar de conduta, de modo a permitir uma reorientação mesma da conduta do doente em cujo corpo se aloja. Assim, diferentemente do pentecostalismo, onde o paciente vivencia de maneira crítica a manifestação do outro em seu corpo, no espiritismo ele torna-se um espectador passivo de um diálogo entre seu duplo e o terapeuta. Embora as exortações dos médiuns sejam dirigidas ao espírito que visam instruir, o sucesso do ritual depende de sua capacidade de instruir o doente e membros do seu círculo de apoio a reorientarem seu comportamento, de acordo com as mudanças que 
observam se verificar no contexto mais amplo da doença (isto é na atitude dos espíritos que definem tal contexto em termos de saúde ou doença).

Benedita recorda-se de como foram violentas as primeiras manisfestações do espírito no corpo da médium: xingava, gritava e recusavase ao diálogo. A mudança gradativa de tal comportamento nas sessões subseqüentes, serviu-lhe de prova de que Adelice começara a trilhar o caminho da cura, embora não se verificassem mudanças correspondentes no estado de Adelice. Neste sentido, podemos dizer que a eficácia do culto residiu não no fato de ter produzido uma reorientação do comportamento de Adelice - o que de fato não se verificou —, mas em ter levado a uma reorientação da postura dos outros - neste caso de Benedita frente a tal comportamento. A atitude do centro frente aos espíritos responsáveis pela doença, marcada pela tolerância e compaixão, permite a Benedita aceitar a identidade ambígua e problemática de Adelice de maneira igualmente tolerante, enquanto identidade processual em curso de desenvolvimento.

\section{OS PROJETOS RELIGIOSOS DE CURA}

O percurso de Benedita através de candomblé, pentecostalismo e espiritismo - bem como as mudanças que se produzem, ao longo deste percurso, em sua postura frente a doença de Adelice - pode ser melhor entendido, quando consideramos os distintos modos de ordenar o mundo que marcam estas religiões.

A visão de mundo pentecostal se assenta sobre uma oposição rígida entre bem e mal; tratam-se, em última instância, de planos descontínuos e irreconciliáveis. Assim, o fiel só compartilha do poder sagrado monopolizado pelo culto ao se aliar definitivamente ao bem (Brandão, 1980; Fernandes, 1982). A doutrina espírita elabora a oposição entre bem e mal, segundo um viés evolucionista - no quadro de uma linha contínua de evolução, o mal corresponde aos níveis inferiores de existência. É através de um processo de desenvolvimento pessoal que o fiel ganha acesso a poder sagrado (Warren, 1984; Droogers, 1989; Greenfield, 1992). No candomblé, bem e mal são realidades situacionais e, portanto, relativas. O mundo é fluxo contínuo de trocas, de modo que para se beneficiar de poder sagrado o adepto do candomblé deve sempre manter uma balança favorável entre favores recebidos e retribuições prestadas. O esforço contínuo de travar e manter alianças, é fundamental para garantir uma posição vantajosa frente ao meio.

Pentecostalismo, espiritismo e candomblé são religiões voltadas para a satisfação de demandas pessoais (diferenciam-se, neste sentido, do catolicismo das CEBs que privilegia as demandas coletivas). A satisfação de demandas, entretanto, não é vista da mesma forma pelos três cultos. No pentecostalismo a resolução de problemas ou aflições individuais deve levar a uma reorientação do comportamento, segundo padrões morais: o fiel pentecostal não bebe, não fuma, não vai a festas etc. $\mathrm{O}$ culto, na verdade, oferece um espaço alternativo que substitui os "prazeres do mundo" pelo prazer das práticas e celebrações religiosas. Visa constituir-se, assim, em um subuniverso de ordem contraposto ao meio circundante.

A satisfação de demandas ao interior do espiritismo busca persuadir o indivíduo a reorientar seu comportamento, segundo uma ética de caridade, da qual deve resultar um modo particular de estar no mundo. O espiritismo não se propõe a transformar o meio nem tampouco a contrapor-se a ele (como o fazem os cultos pentecostais). De seu comprometimento com a promoção do progresso moral dos indivíduos, entretanto, decorre uma proposta implícita de ação sobre o meio social tipicamente expressa no desenvolvimento de práticas assistenciais e de caridade.

No candomblé, por sua vez, a satisfação de demandas pode levar a que o indivíduo venha a assumir determinadas obrigações rituais em um contexto de negociação. $\mathrm{O}$ candomblé não visa modificar nem o indivíduo nem o seu meio, segundo princípios éticos religiosos; propõe-se a fortalecer o indivíduo frente a um meio de constantes ambigüidades e incertezas. Assim, as alianças travadas com os orixás visam equipar o individuo para realizar seus propósitos pessoais no mundo (Prandi, 1991).

Destes três quadros (Tabela 1), resultam maneiras distintas de entender e tratar a doença. Para os pentecostais, a doença é resultante de 
entidades do mal que invadem o corpo. Enquanto expulsão do mal, a cura se processa através de luta. Ao produzir a passagem da aflição à cura, o ritual visa mover o indivíduo através de um espaço ético: libertar-se da doença é deixar o plano do mal e transportar-se para o universo ordenado dos fiéis. Para os espíritas, grande parte das doenças resulta da ação de obsessores ou espíritos menos desenvolvidos (Greenfield, 1992). O ritual recria atividade pedagógica: visa instruir os espíritos obsessores a deixarem o corpo do doente e a trilharem o caminho do progresso moral. Enquanto ação pedagógica, a cura deve constituirse também em instância para o desenvolvimento moral do doente e familiares. No candomblé, a doença resulta da ação prejudicial de outros homens e/ou entidades sobrenaturais; se o indivíduo se abate como conseqüência desta ação é também porque seu corpo está aberto, vulnerável ao meio. A cura envolve essencialmente dinâmica de negociação, visando fortalecer o indivíduo através de alianças com poderes do sagrado.

TABELA 1. Projetos Religiosos de Cura

\begin{tabular}{|c|c|c|c|}
\hline & Pentecostalismo & Espiritismo & Candomblé \\
\hline Visão de Mundo & $\begin{array}{l}\text { - Mundo ordenado, } \\
\text { segundo oposição rígida } \\
\text { entre bem e mal, } \\
\text { entendidos como } \\
\text { universos descontínuos. }\end{array}$ & $\begin{array}{l}\text { - Mundo ordenado } \\
\text { segundo oposição entre } \\
\text { bem e mal, entendidos } \\
\text { como universos contínuos } \\
\text { em uma escala evolutiva. }\end{array}$ & $\begin{array}{l}\text { - Mundo é fluxo contínuo } \\
\text { de trocas entre homens e } \\
\text { seres sobrenaturais. } \\
\text { - Oposição entre bem e mal } \\
\text { é relativizada. }\end{array}$ \\
\hline $\begin{array}{l}\text { Relação com o } \\
\text { Sobrenatural }\end{array}$ & $\begin{array}{l}\text { - Acesso a poder sagrado } \\
\text { se dá através de aliança } \\
\text { definitiva com os poderes } \\
\text { do bem. }\end{array}$ & $\begin{array}{l}\text { - Acesso a poder sagrado } \\
\text { se dá através de processo } \\
\text { de desenvolvimento } \\
\text { pessoal, via auxílio de } \\
\text { espíritos mais } \\
\text { desenvolvidos. }\end{array}$ & $\begin{array}{l}\text { - Acesso a poder } \\
\text { sagrado se dá, } \\
\text { através de alianças pessoais } \\
\text { com entidades } \\
\text { sobrenaturais. }\end{array}$ \\
\hline Relação com o Social & $\begin{array}{l}\text { - Proposta de satisfação de } \\
\text { demandas individuais. } \\
\text { Deve levar a uma clara } \\
\text { reorientação do } \\
\text { comportamento, segundo } \\
\text { determinados padrões } \\
\text { morais. } \\
\text { - Proposta social de } \\
\text { construção de um } \\
\text { subuniverso de ordem } \\
\text { contraposto ao meio } \\
\text { circundante. }\end{array}$ & $\begin{array}{l}\text { - Proposta de satisfação de } \\
\text { demandas individuais. } \\
\text { Deve levar a uma } \\
\text { reorientação do } \\
\text { comportamento segundo } \\
\text { ética de caridade. } \\
\text { • Proposta implícita de } \\
\text { agir sobre o meio via } \\
\text { promoção de } \\
\text { desenvolvimento pessoal } \\
\text { (assistência, educação). }\end{array}$ & $\begin{array}{l}\text { - Proposta de satisfação de } \\
\text { demandas individuais. Pode } \\
\text { levar a determinadas } \\
\text { obrigações no contexto de } \\
\text { uma dinâmica de } \\
\text { negociação. } \\
\text { - Proposta de fortalecimento } \\
\text { do indivíduo frente a um } \\
\text { meio de incertezas e } \\
\text { ambigüidades. }\end{array}$ \\
\hline Visão da Doença & $\begin{array}{l}\text { - Doença causada pela } \\
\text { invasão ou intrusão de } \\
\text { entidades do mal. }\end{array}$ & $\begin{array}{l}\text { - Doença causada pela } \\
\text { interferência ou obsessão } \\
\text { de espíritos menos } \\
\text { desenvolvidos. }\end{array}$ & $\begin{array}{l}\text { - Doença causada pela ação } \\
\text { prejudicial de homens e/ou } \\
\text { entidades sobrenaturais. }\end{array}$ \\
\hline Cura & $\begin{array}{l}\text { - Envolve expulsão } \\
\text { pública do mal. } \\
\text { - Ritual recria dinâmica de } \\
\text { luta. }\end{array}$ & $\begin{array}{l}\text { - Envolve educação dos } \\
\text { espíritos menos } \\
\text { desenvolvidos. } \\
\text { - Ritual recria atividade } \\
\text { pedagógica. }\end{array}$ & $\begin{array}{l}\text { • Envolve o firmar de } \\
\text { alianças para garantir } \\
\text { proteção ao indivíduo. } \\
\text { • Ritual recria dinâmica de } \\
\text { negociação. }\end{array}$ \\
\hline
\end{tabular}




\section{O ITINERÁRIO TERAPÊUTICO}

Se a compreensão dos universos distintos do pentecostalismo, espiritismo e candomblé nos fornece uma chave para entender a história de doença de Adelice, é preciso ter em conta que Benedita não mergulha nestes universos distintos de forma passiva: ela busca a cura de Adelice e, constantemente, (re)avalia os projetos de cada culto, de acordo com seus objetivos.

Benedita ingressa no candomblé sob a orientação de amigos e vizinhos, entre os quais parece existir um consenso quanto ao poder do culto para lidar com problemas mentais. Sustentada por este consenso, freqüenta oito terreiros diferentes; o fracasso de um tratamento não invalida a crença na eficácia do culto. Sempre que deixa um terreiro, Benedita o faz com certa precaução: uma vez que os poderes manipulados pelos especialistas são essencialmente ambíguos é preciso evitar despertar a raiva das mães-de-santo cujas casas abandona. Benedita deixa definitivamente o universo ambíguo do candomblé para ingressar no mundo bem ordenado do pentecostalismo; o contato com pregadores pentecostais influi para minar o consenso sob o qual se assenta sua opção terapêutica pelo candomblé. Para os pentecostais deixar o candomblé significa sair do plano do mal. Entretanto, dos terreiros que freqüentou, Benedita leva consigo o "diagnóstico" que lhe foi dado por uma mãe-de-santo.

No pentecostalismo, o processo diagnóstico insere-se no ritual público de cura; depende da manifestação da entidade maléfica causadora da doença. No candomblé, ao contrário, constitui processo claramente separado do tratamento, um encontro privado que visa reconstituir a cadeia de eventos que produz a aflição. Ao explicar a doença, o especialista do candomblé elabora uma lógica narrativa que permite ao cliente relacionar fatos e sentimentos de sua experiência cotidiana. $\mathrm{O}$ fato de que Benedita retenha a explicação da mãe-de-santo atesta para a força da estratégia interpretativa do candomblé. Talvez mais importante, mostra-nos que, em sua prática, Benedita mescla e reelabora elementos de sistemas distintos que ora aproxima, ora distancia.

Ao deixar a Igreja Universal do Reino de Deus Benedita aproxima o que antes lhe parece- ra radicalmente diferente: no final das contas acaba por concluir que, tanto candomblé, quanto pentecostalismo reservam tempo e espaço privilegiados ao diabo. Contraposto a ambos está o centro espírita, onde acredita ter encontrado a solução potencial para a doença de Adelice. Os símbolos de cura do espiritismo lhe são persuasivos; como parte do tratamento de Adelice, gradativamente se instrui na doutrina do culto.

O desfecho da história de Benedita, entretanto, não foi a conversão. Após um ano de tratamento no centro espírita, Adelice é tida como curada. Benedita é informada pelo presidente do centro de que doravante a manutenção do estado de Adelice depende apenas de sua participação continuada no culto espírita. Não inteiramente satisfeita com o diagnóstico (uma vez que a persistência dos sintomas não a convence quanto a finalização do tratamento), Benedita deixa de freqüentar o centro espírita e passa a investir no sucesso do tratamento psiquiátrico que Adelice nunca abandonou. Quanto à Adelice, ela agora frequienta, não mais acompanhada de sua mãe, um novo templo da Igreja Universal. Aí já não ocupa o papel de paciente a ser curada, mas garante para si um espaço de aceitação parcial. Diverte-se memorizando trechos da Bíblia.

A história de doença de Adelice coloca questões importantes acerca da função terapêutica dos cultos religiosos. Em linhas gerais nos mostra que o sucesso de um determinado projeto religioso de cura, depende da interação de uma série de fatores - incluindo o próprio curso natural da doença - que compõe o contexto sobre o qual agem os indivíduos, participando do evento da doença. Se as visões de mundo que informam o projeto de cura do candomblé, do pentecostalismo e do espiritismo modificam a maneira pela qual Benedita percebe o problema de Adelice, resignificando o contexto da aflição, elas mesmas são modificadas ao serem apropriadas - e por vezes também descartadas - por Benedita.

\section{CONCLUSÃO}

Em trabalho agora clássico, Clifford Geertz define a religião como "um sistema de símbolos 
que atua para estabelecer poderosas, penetrantes e duradouras disposições e motivações nos homens, através da formulação de conceitos de uma ordem de existência geral, e vestindo essas concepções com tal aura de fatualidade que as disposições e motivações parecem singularmente realistas" (1978:104-105). Analisando a trajetória de Adelice e Benedita, através de distintas religiões, percebemos que, diferentemente do que afirma Geertz, a relação entre símbolos religiosos e vida social não é definida a priori por propriedades e significados inerentes aos símbolos, mas estabelecida no curso de eventos concretos nos quais os indivíduos se apropriam, confrontam e reinterpretam os símbolos à luz de determinados fins e interesses. Se estes últimos são por vezes modificados e moldados pela religião, também determinam, em grande medida, a maneira pela qual os projetos religiosos são incorporados ao cotidiano dos indivíduos.

Entender a religiosidade das classes populares urbanas, segundo o modelo de Geertz, é tarefa árdua. A freqüência e aparente facilidade com que membros das classes populares se movimentam entre diferentes cultos questionam, fortemente, a idéia de uma convergência necessária entre projetos religiosos e práticas sociais. Isso significa que os modelos que utilizamos para entender o universo religioso dessas classes devem permitir-nos problematizar as relações mesmas entre os símbolos de uma religião $\mathrm{e}$ as práticas de seus adeptos. Trata-se, fundamentalmente, de abordar a religião sob a perspectiva da experiência religiosa, isto é, das formas pelas quais seus símbolos são vivenciados e continuamente re-significados, através de processos interativos concretos entre indivíduos e grupos.

\section{AGRADECIMENTOS}

Gostaria de agradecer a Paulo César Alves e Iara Souza pela leitura e comentário crítico do texto.

\section{RESUMO}

RABELO, M. C. Religião e Cura: Algumas Reflexões Sobre a Experiência Religiosa das Classes Populares Urbanas. Cad. Saúde Públ., Rio de Janeiro, 9 (3): 316-325, jul/set, 1993.

A importância dos cultos religiosos enquanto agências terapêuticas entre as classes populares urbanas tem sido amplamente reconhecida. A partir de análise da história de doença de uma jovem de bairro pobre de Salvador - que recorreu a uma série de agências religiosas desde a eclosão do seu problema - o presente trabalho busca contribuir para o entendimento das formas pelas quais as visões de mundo e projetos de cura de diferentes cultos são de fato incorporados à experiência cotidiana de doentes e seus familiares.

Palavras-Chave: Religião; Cura; Terapias; Cultura e Doença; Brasil Urbano

\section{REFERÊNCIAS BIBLIOGRÁFICAS}

ALVES, P. C. B., 1990. M edical Culture System: The Social Dimension of Sickness. Tese de Doutorado, Liverpool: University of Liverpool.

BRANDÃO, C. R., 1980. Os Deuses do Povo. São Paulo: Brasiliense.

COMAROFF, J., 1980. Healing and the cultural order: the case of the Barolong boo Ratshidi. A merican Ethnologist, 7: 637-657.

CSORDAS, T., 1983. The rhetoric of transformation in ritual healing. Culture, Medicine and Psychiatry, 7: 333-375.

DROOGERS, A., 1989. The Enigma of the Metaphor that Heals: Signification in an Urban Spiritist Healing Group. Annual Meeting of the American Anthropological Association, Washington D.C. (Mimeo.)

FERNANDES, R. C., 1982. Os Cavaleiros do Bom J esus. São Paulo: Brasiliense.

GEERTZ, C., 1978. A Interpretação das Culturas. Rio de Janeiro: Zahar.

GREENFIELD, S. M., 1992. Spirits and spiritist therapy in southern Brazil: a case study of an innovative, syncretic, healing group. Culture, M edicine and Psychiatry, 16: 23-52.

KAPFERER, B., 1979. Entertaining demons. Social A nalysis, 1: 108-152. 
KLEINMAN, A., 1980. Patients and Healers in the Context of Culture. Berkeley: University of California Press.

LEVI-STRAUSS, C., 1967. A ntropologia Estrutural. Rio de Janeiro: Tempo Brasileiro.

MONTEIRO, D. T., 1977. A cura por correpondência. Religião e Sociedade, 1: 61-79.

MONTERO, P., 1985. Da Doença a Desordem. Rio de Janeiro: Graal.

PRANDI, R., 1991. Os Candomblés de São Paulo. São Paulo: Hucitec.

RABELO, M., 1990. Play and Struggle: Dimensions of the Religious Experience of Peasants in Nova Redençao, Bahia. Tese de Doutorado, Liverpool: University of Liverpool.
TURNER, V., 1967. The Forest of Symbols. Ithaca: Cornell University Press. , 1975. Revelation and Divination in N dembu Ritual. Ithaca: Cornell University Press. WARREN, D., 1984. A terapia espírita no Rio de Janeiro por volta de 1900. Religião e Sociedade, 11: 56-83.

WILLIAMS, P., 1979. Primitive Religion and Healing. Cambridge: Brewer. 